\title{
Evaluasi Pemanfaatan Laboratorium Biologi SMAN/MAN se-kecamatan Godean
}

\author{
Tri Erna Romadhoni, Much. Fuad Saifuddin* \\ Program Studi Pendidikan Biologi, Fakultas Keguruan dan Ilmu Pendidikan \\ Universitas Ahmad Dahlan, Jl. Jendral Ahmad Yani (Ringroad Selatan) Tamanan, \\ Banguntapan, Bantul, Daerah Istimewa Yogyakarta 55191 \\ triernaromadhoni@gmail.com,*fuad.saifuddin@pbio.uad.ac.id
}

\begin{abstract}
The laboratory has an important role in the implementation of learning, especially in the form of practicum. The use of school laboratories needs to be evaluated as a form of running school management. This study aims to determine: 1) the Principal's carrying capacity (contexts); 2) Resources support (input); 3) Laboratory utilization and constraints (process); 4) The percentage of students' interest in studying in the laboratory (product). This evaluation research uses the context, input, process, and product (CIPP) model. The research subjects were school principals, laboratory heads in SMA/MA Negeri in Godean sub-district, laboratory assistants at SMA N 1 Godean, two biology teachers from each school, and students SMA N 1 Godean 89 people and MAN 1 Sleman 80 people using proportionate stratified random sampling. The research object is the use of biological laboratories. Data collection techniques used are observation, interviews, questionnaires, and documentation. The data analysis technique used is in the form of qualitative and quantitative descriptive analysis. The evaluation results by CIPP obtained: 1) Context, the support capacity provided by the Principal by facilitating laboratory utilization activities; 2) Input, the availability of infrastructure suggestions is used to support learning through practicum and demonstrations. Management is carried out by laboratory personnel. Management includes planning, arrangement, arrangement, monitoring, and evaluation; 3) Process, the laboratory is used based on its function. The obstacles faced are infrastructure, limited time, and human resources; 4) Product, the percentage of student interest in learning in the laboratory of SMA N 1 Godean is $94.01 \%$ and MAN 1 Sleman is $91.39 \%$.
\end{abstract}

Keywords : CIPP, Evaluation, Biology laboratory

This is an open access article distributed under the Creative Commons 4.0 Attribution License, which permits unrestricted use, distribution, and reproduction in any medium, provided the original work is properly cited. $\odot 2018$ by author and Universitas Negeri Padang.

\section{PENDAHULUAN}

Sekolah Menengah Atas (SMA) adalah salah satu bentuk satuan pendidikan formal yang menyelenggarakan pendidikan umum jenjang pendidikan menengah. Satuan pendidikan dalam mencapai tujuan pendidikan didukung oleh beberapa komponen seperti pendidik, peserta didik, sarana dan prasarana serta kurikulum. Komponen-komponen tersebut harus saling bersinergi agar dapat menjalankan tujuan pendidikan dengan efektif.

Salah satu komponen yang ada adalah sarana prasarana yang dimanfaatkan untuk menunjang kegiatan pembelajaran. Menurut Peraturan Menteri Pendidikan Nasional No. 24 (2007b), salah satu sarana yang dimiliki Sekolah Menengah Atas adalah laboratorium biologi yang berguna untuk menunjang pembelajaran biologi. Mata pelajaran biologi dalam pelaksanaannya memerlukan teori dan praktik. Praktik dilakukan untuk membuktikan hasil teori yang diperoleh selama pembelajaran di dalam kelas.

Laboratorium atau yang sering disingkat "lab", merupakan tempat untuk melakukan penelitian, percobaan ataupun pelatihan ilmiah (Decaprio, 2013) dan membentuk pengalaman peserta didik berinteraksi dengan materi/bahan untuk mengamati dan memahami alam (Hofstein \& Mamlok-Naaman, 2007). Kegiatan praktikum di laboratorium telah menjadi bagian yang tidak terpisahkan dalam pembelajaran biologi, karena dapat memberikan pengalaman dan keterampilan. Peserta didik memperoleh kesempatan untuk melihat dan membuktikan konsep atau teori dengan pengamatan langsung melalui kegiatan praktikum, sehingga dapat memperkuat pemahaman peserta didik. Apabila peserta didik lebih paham terhadap materi pelajaran diharapkan hasil belajar pun akan meningkat. 
Pemanfaatan laboratorium merupakan suatu proses penggunaan sarana laboratorium dengan teknik atau cara tertentu untuk menunjang pembelajaran, sehingga tujuan pembelajaran yang diharapkan dapat tercapai (Hidayati, 2013). Laboratorium biologi tentu harus memenuhi standar minimal terkait dengan kelengkapan sarana atau alat sesuai dengan standar sarana dan prasarana. Alat-alat laboratorium dapat dimanfaatkan untuk demostrasi di dalam kelas, praktikum di laboratorium maupun pengamatan di lingkungan sekolah.

Peraturan Menteri Pendidikan Nasional No. 24 Tahun 2007 menyatakan bahwa laboratorium berfungsi sebagai tempat berlangsungnya kegiatan pembelajaran biologi secara praktik yang memerlukan peralatan khusus (Kementerian Pendidikan dan Kebudayaan, 2007b). Selain dari segi sarana atau alat, pemanfaatan laboratorium biologi harus dimanfaatkan secara optimal dalam kegiatan praktikum. Hal tersebut perlu dilakukan untuk menunjang pembelajaran biologi sehingga peserta didik memperoleh pemahaman secara optimal, baik secara teori maupun praktik.

Berdasarkan observasi awal yang dilakukan di salah satu sekolah menengah atas di kecamatan Godean ditemukan informasi bahwa masih ada yang belum mempunyai laboran. Peralatan laboratorium tidak tersedia dalam jumlah dan kualitas memadai. Masih kurangnya perawatan alat-alat dan bahan-bahan karena sumber daya manusia yang terbatas. Pembelajaran biologi sering kali hanya disampaikan melalui materi. Hal tersebut dikhawatirkan dapat menghambat pembelajaran biologi khususnya praktikum, maka perlu dilakukan evaluasi tentang pemanfaatan laboratorium agar laboratorium biologi dapat digunakan sebagai metode untuk mendukung proses pembelajaran biologi khususnya praktikum. Evaluasi merupakan proses sistematis dan berkelanjutan untuk menentukan kualitas (nilai dan arti) dari sesuatu, berdasarkan kriteria tertentu (Arifin, 2009). Tujuan adanya evaluasi untuk mengetahui pencapaian tujuan program apakah komponen dan sub komponen sudah terlaksana atau belum.

Evaluasi terkait pemanfaatan laboratorium pernah dilakukan oleh Sundari (2013), yang menunjukkan pemanfaatan laboratorium dalam kategori baik. Namun detail pemanfaatan laboratorium belum tersampaikan. Penelitian ini menggunakan model evaluasi CIPP (Context, Input, Prosess Product) yang mencakup perencanaan, pengelolaan, pelaksanaan, pengawasan, hingga capaian program. Penelitian ini diharapkan dapat menjadi acuan perbaikan dalam perbaikan pemanfaatan laboratorium biologi yang berkaitan: 1) daya dukung kepala sekolah (contexs); 2) sumber daya dukung dalam pemanfaatan laboratorium biologi (input); 3) pemanfaatan laboratorium dan kendala-kendala (process); 4) persentase minat peserta didik belajar di laboratorium (product).

\section{METODE PENELITIAN}

Penelitian ini termasuk penelitian deskriptif yang dilakukan dengan model contexs, input, process, and product (CIPP). Penelitian ini dilakukan di SMA/MA Negeri se-kecamatan Godean, yaitu SMA Negeri 1 Godean dan MAN 1 Sleman dengan subjek penelitian adalah kepala sekolah, kepala laboratorium di SMA/MA Negeri se-kecamatan Godean, laboran hanya di SMA N 1 Godean, 2 guru biologi masing-masing sekolah dengan menggunakan purposive sampling dan peserta didik di SMA N 1 Godean 89 orang dan MAN 1 Sleman 80 orang dengan menggunakan proportionate stratified random sampling. Objek penelitian adalah tentang pemanfaatan laboratorium biologi.

Teknik pengumpulan data melalui observasi, wawancara, kuesioner dan dokumentasi. Instrumen yang digunakan berupa lembar pedoman wawancara, angket dan lembar pengamatan dengan kisi-kisi seperti yang terdapat pada suplementary. Instrumen telah melalui proses validasi secara expert judgment oleh dua dosen ahli dan dinyatakan valid.

Teknik analisis data yang digunakan berupa analisis deskriptif kualitatif dan kuantitatif. Data kualitatif diperoleh dari wawancara dan dokumentasi, sedangkan data kuantitatif diperoleh dari kuisioner. Data kualitatif diinterpretasikan dengan panduan interaktif model Miles dan Huberman (1994) dari komponen pengumpulan data, reduksi data, penyajian data dan kesimpulan.

Data yang diperoleh dari angket guru dan peserta didik kemudian dianalisis dengan cara tabulasi semua data yang diperoleh untuk setiap indikatornya. Skor yang telah dihitung kemudian dipersentasekan menggunakan rumus I.

$$
P=\frac{S}{N} \times 100 \%
$$

Keterangan:

$\mathrm{P}:$ Angka persen 
S : Jumlah skor yang diperoleh

$\mathrm{N}$ : Jumlah skor tertinggi

(Sugiyono, 2016)

Hasil persentase diubah menjadi kategori dengan pemaknaan persentase mengacu pada Tabel 1.

Tabel 1. Kriteria penilaian

\begin{tabular}{cl}
\hline Interval Persentase & \multicolumn{1}{c}{ Kriteria } \\
\hline $85 \%-100 \%$ & Sangat Tinggi \\
$70 \%-84,99 \%$ & Tinggi \\
$55 \%-69,99 \%$ & Sedang \\
$40 \%-54,99 \%$ & Rendah \\
$<39,99 \%$ & Sangat Rendah \\
\hline
\end{tabular}

(Sugiyono, 2016)

\section{HASIL DAN PEMBAHASAN}

Laboratorium biologi SMA sangat penting untuk mendukung proses pembelajaran biologi agar terlaksana dengan baik, selain itu dapat juga berperan sebagai sumber belajar. Oleh karena itu, laboratorium harus memenuhi sarana dan prasarana yang telah ditetapkan. Laboratorium yang dimanfaatkan dengan benar, baik dari segi sarana maupun fungsi laboratorium diharapkan dapat meningkatkan kualitas pendidikan khususnya pembelajaran biologi. Hasil evaluasi pemanfaatan laboratorium biologi dengan model CIPP:

\section{Contexts}

Daya dukung kepala sekolah dibutuhkan dalam pemanfaatan laboratorium. Dukungan yang diberikan berupa pemenuhan fasilitas yang diperlukan dalam pemanfaatan laboratorium. Hal ini dilakukan sebagai komitmen kepala sekolah untuk meningkatkan kualitas pembelajaran. Menurut Hidayati (2013), dukungan kebijakan kepala sekolah merupakan salah satu indikator untuk mengetahui cara pemanfaatan laboratorium. Dukungan kebijakan kepala sekolah penting, karena dikeluarkannya kebijakan berarti pembelajaran praktikum memperoleh dukungan kuat. Dukungan tidak hanya sebatas aspek legalitas, tetapi berbagai aspek lainnya seperti aspek sarana prasarana, ketenagaan, pendanaan dan sebagainya.

Kepala sekolah juga melakukan monitoring dan evaluasi program kegiatan di sekolah. Hal ini sesuai dengan PERMENDIKNAS No 13 tahun 2007 tentang standar kepala sekolah, bahwa kepala sekolah harus mempunyai kompetensi kepribadian, manajerial, kewirausahaan, supervisi, dan sosial (Kementerian Pendidikan dan Kebudayaan, 2007a). Kepala sekolah memiliki peran dalam meningkatkan mutu pendidikan yaitu sebagai educator, manajer, administrator, leader, innovator dan motivator (Fitrah, 2017). Selain itu, kepala sekolah berserta pengawas memiliki peran dalam supervise pembelajaran disekolah untuk meningkatkan kompetensi guru dalam pemanfaatan laboratorium agar dilakukan secara maksimal (Handayani, 2018).

Kepala SMA N 1 Godean dan kepala MAN 1 Sleman mendukung dan memfasilitasi setiap kegiatan yang berkaitan untuk kemajuan sekolah. Minimnya daya dukung dapat menyebabkan laboratorium tidak sesuai dengan standar baik dari sisi desain tata letak maupun ketersedian sarana dan prasarana (Anggraeni, 2013; Indriastuti, Herlina, \& Widiyaningrum, 2013). Salah satu hal yang dilakukan kepala sekolah dalam mendukung pemanfaatan laboratorium adalah dengan melakukan memonitor dan mengevaluasi. Tugas memonitoring dan mengevaluasi sesuai dengan PERMENDIKNAS No 13 tahun 2007 kompetensi manajerial poin 2.16 melakukan monitoring, evaluasi dan pelaporan pelaksanaan program kegiatan sekolah/madrasah dengan prosedur yang tepat, serta merancang tindak lanjutnya (Kementerian Pendidikan dan Kebudayaan, 2007a).

\section{Input}

Evaluasi input dilihat dari ketersediaan sarana prasarana laboratorium dan pengelolaan laboratorium. Ketersediaan sarana dan prasarana dibutuhkan di laboratorium biologi sebagai dukungan fisik terhadap pelaksanaan pemanfaatan laboratorium. Ketersediaan alat bahan akan membantu pelaksanaan kegiatan pemanfaatan laboratorium seperti kegiatan praktikum dan demonstrasi. Serta dapat meningkatkan atau mengoptimalkan keberhasilan proses kegiatan belajar mengajar. Menurut Firmansyah, Supriyanto, dan Timan (2018), ketersediaan sarana prasarana merupakan fasilitas langsung ataupun tidak langsung dalam mencapai tujuan pendidikan.

Analisis kebutuhan pengadaan alat bahan di laboratorium selalu dilakukan sebelum tahun ajaran baru. Analisis dilakukan berdasarkan skala prioritas kegunaannya. Analisis kebutuhan 
pengadaan alat bahan laboratorium dilakukan untuk mengetahui alat bahan atau sarana laboratorium yang dibutuhkan dan belum terpenuhi. Analisis dilakukan oleh kepala laboratorium berdasarkan usulan dari guru biologi. Analisis kebutuhan termasuk perencanaan (Kementerian Pendidikan dan Kebudayaan, 2008), hal ini tercantum dalam kompetensi manajerial poin 3.1 merencanakan kegiatan dan pengembangan laboratorium sekolah/madrasah.

Secara umum peralatan dan bahan di laboratorium SMA/MA N Godean tersedia dengan baik dan memadai. Kelengkapan alat bahan praktikum merupakan komponen yang sangat menunjang berjalannya kegiatan pemanfaatan laboratorium. Menurut Wahyunidar (2017) laboratorium dikatakan efektif apabila memenuhi indikator: 1) frekuensi penggunaan laboratorium; 2) kelengkapan alat dan bahan yang ada di laboratorium; 3 ) alat yang tersedia sesuai dengan materi pembelajaran; dan 4) alokasi waktu yang cukup untuk kegiatan praktikum.

Laboratorium memiliki luas yang memadai dengan ruang penyimpanan didalamnya. Namun, pencahayaan sedikit kurang karena kanan kiri laboratorium ada bangunan. Kementerian Pendidikan dan Kebudayaan (2007b) menetapkan bahwa ruang laboratorium biologi memiliki fasilitas yang memungkinkan pencahayaan memadai untuk membaca buku dan mengamati obyek percobaan. Ruang laboratorium di MAN 1 Sleman masih bergabung dengan mata pelajaran lain yaitu biologi dan kimia. Selain itu hasil observasi juga menemukan masalah air masih belum memenuhi syarat. Sedangkan, keberadaan air sangat penting, selain digunakan untuk bahan praktikum biologi, air juga untuk membersihkan peralatan yang selesai digunakan dan pertolongan pertama pada kecelakaan kerja. Selain itu air juga untuk menjaga kebersihan ruang laboratorium. Menurut Firmansyah et al., (2018) pemanfaatan sarana dan prasarana sekolah adalah salah satu indikator yang digunakan sebagai ukuran tingkat baik atau buruknya pelayanan yang diberikan sekolah. Penggunaan yang tepat diharapkan dapat menunjang dan mendukung tercapainya tujuan pembelajaran. Pemanfaatan yang baik adalah penggunaan disesuaikan dengan kebutuhan.

Pengelolaan laboratorium juga termasuk dalam evaluasi input. Perencanaan program kerja merupakan fungsi utama dalam pengelolaan laboratorium. Menurut Decaprio (2013) Pengelolaan laboratorium tanpa sebuah perencanaan, akan menjadikan laboratorium berjalan tanpa visi dan misi yang jelas serta sulit menentukan arah pengembangan.

Perencanaan ini mencakup program tahunan dan semester, tujuan yang akan dicapai, jadwal penggunaan praktikum, pengadaan alat bahan laboratorium dan inventarisasi. Kepala laboratorium bertugas untuk menyusun program pengelolaan laboratorium (Kementerian Pendidikan dan Kebudayaan, 2008).

Pengelolaan laboratorium memerlukan struktur organisasi pengelola laboratorium untuk memperjelas posisi dan wewenangnya. SMA N 1 Godean dan MAN 1 Sleman belum ada struktur organisasi yang dipanjang di laboratorium. Menurut Rahmiyati (2013) selain sarana prasarana yang memadai, guru juga memiliki peran yang sangat besar sebagai pengelola laboratorium. Guru diharapkan mampu memiliki kemampuan manajerial dan kemampuan individu dalam melakukan perencanaan, pengorganisasian, pelaksanaan dan mengevaluasi segala hal yang berkaitan dengan pembelajaran di laboratorium.

Keberadaan alat bahan di laboratorium memerlukan perlakuan khusus sesuai sifat dan karakteristiknya untuk mengurangi resiko kerusakan. Pengaturan dan penyimpanan alat bahan di SMA N 1 Godean sudah dipisahkan pada almari yang berbeda. Penyimpanan peralatan juga berdasarkan pada jenis dasar alat karena untuk menghindari kerusakan. Penyimpanan di MAN 1 Sleman masih bercampur hanya dipisahkan antara alat dan bahan. Hal ini dikarenakan MAN 1 Sleman belum memiliki laboran. Pengaturan dan penyimpanan peralatan dan bahan praktikum merupakan tugas laboran hal ini tertera dalam PERMENDIKNAS No. 26 tahun 2008 tentang standar tenaga laboratorium. Penataan alat bahan dan membersihkan setelah digunakan merupakan upaya pemeliharaan alat bahan di laboratorium. Menurut Bafadal (2008) terdapat 4 macam pemeliharaan perlengkapan pendidikan berdasarkan sifatnya yaitu: (1) bersifat pengecekan, (2) bersifat pencegahan, (3) bersifat perbaikan ringan dan (4) perbaikan berat.

Pengecekan secara berkala dilakukan secara rutin di SMA N 1 Godean dengan mengecek kebersihan alat dan penyimpanan alat dan bahan yang masuk atau rusak langsung dimasukkan kedalam inventaris. Pemeliharan alat dan bahan di MAN 1 Sleman belum dilakukan karena 
keterbatasan waktu dan sumber daya manusia atau laboran. Perawatan merupakan bagian dari pemanfaatan laboratorium, karena merupakan upaya dalam menjaga keawetan sarana laboratorium agar dapat dimanfaatkan dalam menunjang pembelajaran. Oleh karena itu, keberadaan alat-alat laboratorium harus dijaga dengan melakukan perawatan yang baik, seperti menjaga kebersihannya, dikembalikan ditempat semula dan disimpan di tempat yang baik agar tidak mudah kotor. Perawatan merupakan salah satu indikator tentang cara pemanfaatan laboratorium (Hidayati, 2013).

Menurut Sundari (2013) evaluasi merupakan proses penentuan hasil yang dicapai beberapa kegiatan yang direncanakan untuk tercapainya tujuan. Pengawasan dan evaluasi kegiatan laboratorium dilakukan oleh pengawas satu tahun sekali dan dari sekolah satu semester sekali secara rutin. Aspek yang dipantau di SMA N 1 Godean seputar program, kegiatan dan terutama alat-alat yang dibutuhkan serta kerusakan-kerusakan yang ada. Aspek yang pantau di MAN 1 Sleman tentang kelengkapan alat dan bahan, kebersihan, kenyamanan ruangan dan administrasi.

\section{Process}

Pada tahap ini evaluasi yang dilakukan terkait dengan kegiatan pemanfaatan laboratorium dan kendala-kendala yang dihadapi oleh guru. Kegiatan pemanfaatan laboratorium, seperti kegiatan praktikum merupakan bagian dari proses kegiatan belajar mengajar. Laboratorium dimanfaatkan dalam kegiatan praktikum diharapkan dapat menunjang pemahaman peserta didik sebagaimana tersaji pada tabel 2 .

Tabel 2. Hasil Angket Guru Tentang Pemanfaatan Laboratorium

\begin{tabular}{l|c|c}
\hline \multicolumn{1}{c|}{ Pernyataan } & $\begin{array}{c}\text { SMA } \\
\text { Godean }\end{array}$ & $\begin{array}{c}\text { MAN } \\
\text { Sleman }\end{array}$ \\
\hline $\begin{array}{l}\text { Laboratorium untuk } \\
\text { pembelajaran biologi }\end{array}$ & 2 & 2 \\
\hline $\begin{array}{l}\text { Laboratorium untuk } \\
\text { demonstrasi }\end{array}$ & 2 & 1 \\
\hline $\begin{array}{l}\text { Laboratorium untuk } \\
\text { penelitian (riset) }\end{array}$ & 1 & 2 \\
\hline $\begin{array}{l}\text { Menumbuhkan moti- } \\
\text { vasi }\end{array}$ & 2 & 2 \\
\hline
\end{tabular}

\begin{tabular}{|c|c|c|}
\hline $\begin{array}{lr}\begin{array}{l}\text { Memberikan } \\
\text { trampilan }\end{array} & \text { ke } \\
\text { ilmiah } & \text { kerja } \\
& \end{array}$ & 2 & 2 \\
\hline Jumlah & 9 & 9 \\
\hline Persentase & $90,00 \%$ & $90,00 \%$ \\
\hline Kategori & $\begin{array}{c}\text { Sangat } \\
\text { tinggi }\end{array}$ & $\begin{array}{c}\text { Sangat } \\
\text { tinggi }\end{array}$ \\
\hline
\end{tabular}

Laboratorium biologi dapat dimanfaatkan untuk mendukung proses pembelajaran biologi. Kesesuaian sarana dan prasarana di laboratorium akan memberikan pengalaman yang nyata bagi peserta didik, sehingga diharapkan peserta didik dapat menguasai kompetensi yang telah ditentukan. Serta diharapkan mampu meningkatkan minat belajar biologi peserta didik.

Berdasarkan Tabel 2 guru telah memanfaatkan laboratorium dalam pembelajaran biologi karena biologi mengkaji tentang alam untuk membuktikannya perlu dipraktikkan di laboratorium. Laboratorium bermanfaat dalam menunjang keberhasilan pembelajaran biologi melalui praktikum, karena materi lebih terekam. Menurut Yuliana, Hala, dan Taiyeb (2017) pembelajaran biologi dengan memanfaatkan laboratorium dapat memberikan pengalaman dengan langsung mengamati preparat, mendalami dan memahami materi serta dapat mengarahkan peserta didik untuk aktif belajar.

Laboratorium juga digunakan sebagai tempat demonstrasi seperti mengenalkan alat-alat laboratorium. Kegiatan demonstrasi juga dilakukan apabila peralatan dan waktu yang tersedia tidak mencukupi. Pemanfaatan laboratorium berdasarkan fungsinya dapat digunakan sebagai tempat melakukan percobaan, penelitian, eksperimen, penunjang kegiatan kelas, display/pameran, tempat koleksi sejumlah species langka dan sebagai tempat museum kecil (Hidayati, 2013).

Pembelajaran biologi di laboratorium MAN 1 Sleman disesuaikan dengan KD. Laboratorium secara efektif digunakan untuk kegiatan pembelajaran dalam bentuk praktikum, pemanfaatan peralatan untuk observasi lingkungan dan demonstrasi (jika jumlah alat terbatas). Laboratorium sangat penting untuk memberikan pengalaman peserta didik seperti cara memegang atau menggunakan mikroskop dan melihat benda-benda kecil. Laboratorium digunakan sebagai sumber belajar dan media pembelajaran sehingga mencapai tujuan pembelajaran. Selain 
itu juga menumbuhkan motivasi peserta didik bahwa belajar biologi itu menyenangkan serta menumbuhkan sikap jujur, teliti dan kerja sama. Respon peserta didik terhadap pemanfaatan laboratorium tersaji pada tabel 3 .

Laboratorium berfungsi untuk menyeimbangkan teori dan praktik, melalui praktik dapat memberi ketrampilan kerja ilmiah kepada peserta didik. Selain itu aktivitas di laboratorium dapat bermanfaat bagi peserta didik: (1) memupuk rasa keberanian, rasa ingin tahu dan percaya diri; (2) menambah ketrampilan menggunakan alat/media yang ada di laboratorium; (3) memecahkan masalah; dan (4) sarana belajar untuk memahami materi yang bersifat abstrak menjadi konkret (Decaprio, 2013).

Tabel 3. Hasil Angket Peserta didik Tentang Pemanfaatan Laboratorium

\begin{tabular}{l|c|c}
\hline \multicolumn{1}{c|}{ Pernyataan } & $\begin{array}{c}\text { SMA } \\
\text { Godean }\end{array}$ & $\begin{array}{c}\text { MAN } \\
\text { Sleman }\end{array}$ \\
\hline $\begin{array}{l}\text { Laboratorium untuk } \\
\text { pembelajaran biologi }\end{array}$ & 88 & 74 \\
\hline $\begin{array}{l}\text { Laboratorium untuk } \\
\text { demonstrasi }\end{array}$ & 83 & 40 \\
\hline $\begin{array}{l}\text { Laboratorium untuk } \\
\text { science club }\end{array}$ & 30 & 47 \\
\hline $\begin{array}{l}\text { Menumbuhkan } \\
\text { motivasi }\end{array}$ & 89 & 76 \\
\hline $\begin{array}{l}\text { Memberikan ketrampilan kerja } \\
\text { ilmiah } \\
\text { penggunaan dan } \\
\text { peralatan praktikum }\end{array}$ & 89 & 77 \\
\hline \multicolumn{1}{c|}{ Jumlah } & 379 & 314 \\
\hline \multicolumn{1}{c|}{ Kategori } & $85,17 \%$ & $78,50 \%$ \\
\hline
\end{tabular}

Berdasarkan tabel 3 Hasil angket peserta didik di MAN 1 Sleman lebih rendah dari SMA N 1 Godean, laboratorium kurang dimanfaatkan untuk kegiatan demonstrasi dan kegiatan science club. Pemanfaatan laboratorium berdasarkan fungsinya dapat digunakan sebagai tempat melakukan percobaan, penelitian, eksperimen, penunjang kegiatan kelas, display/pameran, tempat koleksi sejumlah species langka dan sebagai tempat museum kecil (Hidayati, 2013).

Pemanfaatan laboratorium untuk kegiatan praktikum dalam pelaksanaannya rata-rata sudah terlaksana dengan baik. Namun, masih ada beberapa kendala yang dihadapi guru dalam pemanfaatan laboratorium seperti pada tabel 4 .
Tabel 4. Kendala-Kendala Pemanfaatan Laboratorium

\begin{tabular}{l|c|c}
\hline \multicolumn{1}{c|}{ Pernyataan } & $\begin{array}{c}\text { SMA } \\
\text { Godean }\end{array}$ & $\begin{array}{c}\text { MAN } \\
\text { Sleman }\end{array}$ \\
\hline Sarana prasarana & 1 & 1 \\
\hline Laboran & 0 & 2 \\
\hline Ketersediaan waktu & 2 & 2 \\
\hline Jumlah & 3 & 5 \\
\hline Persentase & $50,00 \%$ & $83,33 \%$ \\
\hline Kategori & Rendah & Tinggi \\
\hline
\end{tabular}

Berdasarkan tabel 4 MAN 1 Sleman lebih tinggi dengan persentase $83,33 \%$. Faktor yang dapat menyebabkan bergesernya fungsi laboratorium yaitu laboratorium dijadikan kelas, tempat rapat, tempat kegiatan ekstrakulikuler seperti menari, ataupun Gudang. Selain ruangan ketersediaan waktu juga menjadi kendala, pembagian jadwal yang tidak tepat, atau waktu bersamaan dengan hari libur otomatis kegiatan praktikum akan bergeser. Ketersediaan alat dan bahan juga menjadi kendala apabila ada alat yang rusak. Faktor lain yang menjadi kendala adalah sumber daya manusia, seperti tidak adanya laboran (Sobiroh, 2005).

Berdasarkan penelitian yang dilakukan Nuada dan Harahap (2015) menemukan faktor-faktor yang dapat menghambat dalam pemanfaatan laboratorium adalah perlengkapan yang tidak memadai. Tidak adanya pengelola atau laboran. Kompetensi guru dalam memahami penggunaan alat dan bahan masih kurang. Serta waktu pelaksanaan kegiatan praktikum yang kurang.

Salah satu kendala yang dihadapi guru adalah tidak adanya laboran. Guru harus menyiapkan sendiri sebelum melakukan praktikum termasuk membersihkan dan mengecek. Laboran berperan penting dalam menunjang keterlaksanaan kegiatan praktikum mulai penyiapan alat bahan, membantu membersihkan dan mengembalikan alat bahan ke tempat semula. Laboran juga berperan dalam mengelola laboratorium seperti pengecekan alat bahan yang rusak dan habis, pengaturan penempatan alat bahan, menangani administrasi serta menjaga kebersihan, keselamatan dan keamanan laboratorium (Sundari, 2013). Kendala lain yang dihadapi guru adalah masalah waktu. Guru harus lebih pandai membuat strategi untuk mengatasi keterbatasan waktu.

\section{Product}

Evaluasi produk dilakukan terhadap minat peserta didik terhadap kegiatan laboratorium. 
Peserta didik cenderung memiliki minat lebih Ketika belajar di laboratorium. Motivasi peserta didik akan meningkat ketika memperoleh hal baru, seperti kegiatan yang dilakukan di laboratorium. Rasa ingin tahu peserta didik akan meningkat jika melakukan percobaan atau eksperimen yang sebelumnya belum pernah mereka lakukan (Sobiroh, 2005). Minat peserta didik untuk belajar di laboratorium tersaji pada tabel 5 .

Tabel 5. Hasil Angket Minat Belajar di Laboratorium

\begin{tabular}{c|c|c}
\hline \multicolumn{1}{c|}{ Pernyataan } & $\begin{array}{c}\text { SMA } \\
\text { Godean }\end{array}$ & $\begin{array}{c}\text { MAN } \\
\text { Sleman }\end{array}$ \\
\hline $\begin{array}{l}\text { Minat peserta didik } \\
\text { belajar di } \\
\text { Laboratorium }\end{array}$ & 753 & 658 \\
\hline Persentase & $94,01 \%$ & $91,39 \%$ \\
\hline Kategori & $\begin{array}{c}\text { Sangat } \\
\text { tinggi }\end{array}$ & $\begin{array}{c}\text { Sangat } \\
\text { tinggi }\end{array}$ \\
\hline
\end{tabular}

Berdasarkan tabel 5 diketahui minat peserta didik belajar di laboratorium SMA Godean lebih tinggi. Hal ini menandakan kegiatan di laboratorium lebih menarik, peserta didik senang melakukan kegiatan praktikum di laboratorium, tidak merasa jenuh karena yang diajarkan bukan hanya teori. Interaksi peserta didik dengan objek fisik secara langsung dan mandiri dapat membentuk pengetahuan mereka. Salah satu faktor yang mempengaruhi belajar peserta didik adalah minat yang diartikan sebagai keingintahuan seseorang tentang suatu objek (Mardapi, 2008). Minat juga merupakan salah satu faktor untuk mencapai tujuan pembelajaran.

Berdasarkan penelitian yang dilakukan Sundari (2013) pembelajaran di laboratorium lebih menarik. Selain itu, Peserta didik lebih semangat, antusias dalam mempersiapkan diri, lebih aktif bertanya ketika di laboratorium. pembelajaran di laboratorium dapat digunakan dalam membedakan antara peserta didik dengan minat tinggi dan yang tidak, karena minat dan sikap antusias serta ketertarikan akan menyebabkan peserta didik belajar dan bekerja tekun, teliti dan jujur.

\section{KESIMPULAN}

Volume 5| Nomor 1|Mei 2021|Page 59-67
Berdasarkan hasil penelitian dan pembahasan di atas, maka dapat disimpulkan bahwa evaluasi pemanfaatan laboratorium biologi adalah sebagai berikut: 1) Daya dukung yang diberikan kepala sekolah dengan memfasilitasi kegiatan pemanfaatan laboratorium serta melakukan monitoring dan evaluasi pemanfaatan laboratorium (contexs); 2) Ketersediaan saran prasarana digunakan untuk mendukung pembelajaran melalui praktikum dan demostrasi. Pengelolaan dilakukan oleh tenaga laboratorium. Pengelolaan mencakup perencanaan, pengaturan dan penataan, pengawasan dan evaluasi (input); 3) Laboratorium dimanfaatkan berdasarkan fungsinya. Kendala yang dihadapi adalah sarana prasarana, keterbatasan waktu dan sumber daya manusia (process); 4) Persentase minat peserta didik belajar di laboratorium SMA N 1 Godean 94,01\% dan MAN 1 Sleman 91,39\% (product).

\section{DAFTAR PUSTAKA}

Anggraeni, A. (2013). Pengelolaan laboratorium biologi untuk menunjang kinerja pengguna dan pengelola laboratorium biologi SMA Negeri 2 Wonogiri. Semarang: Universitas Negeri Semarang. Retrieved from https://lib.unnes.ac.id/18680/

Arifin, Z. (2009). Evaluasi pembelajaran. Jakarta: Remaja Rosdakarya.

Bafadal, I. (2008). Manajemen perlengkapan sekolah teori dan aplikasinya. Jakarta: Bumi Aksara.

Decaprio, R. (2013). Tips mengelola laboratorium sekolah. Yogyakarta: DIVA Press.

Firmansyah, T., Supriyanto, A., \& Timan, A. (2018). Efektivitas pemanfaatan sarana dan prasarana dalam meningkatkan mutu layanan. JMSP (Jurnal Manajemen Dan Supervisi Pendidikan), 2(3), 179-184. https://doi.org/10.17977/um025v2i32018p 179

Fitrah, M. (2017). Peran kepala sekolah dalam meningkatkan mutu pendidikan. Jurnal Penjaminan Mutu, 3(1), 31-42. https://doi.org/10.25078/jpm.v3i1.90

Handayani, M. (2018). Pemanfaatan sarana 
laboratorium di SMA yang telah dan belum melaksanakan kurikulum 2013. Jurnal Pendidikan Dan Kebudayaan, 3(2), 152166. https://doi.org/10.24832/jpnk.v3i2.658

Hidayati, U. (2013). Pemanfaatan laboratorium IPA dan Bahasa pada Madrasah Aliyah Swasta. EDUKASI: Jurnal Penelitian Pendidikan Agama Dan Keagamaan, 11(1), 94-112. Retrieved from http://jurnaledukasikemenag.org/index.php /edukasi/article/download/428/367

Hofstein, A., \& Mamlok-Naaman, R. (2007). The laboratory in science education: the state of the art. Chem. Educ. Res. Pract., 8(2), 105107. https://doi.org/10.1039/B7RP90003A

Indriastuti, I., Herlina, L., \& Widiyaningrum, P. (2013). Kesiapan laboratorium biologi dalam menunjang kegiatan praktikum SMA Negeri di kabupaten Brebes. Journal of Biology Education, 2(2), 124-132. Retrieved from https://journal.unnes.ac.id/sju/index.php/uj be/article/view/2834

Kementerian Pendidikan dan Kebudayaan. Standar Kepala Sekolah/Madrasah., Pub. L. No. 13 (2007). Indonesia: Kementerian Pendidikan dan Kebudayaan RI.

Kementerian Pendidikan dan Kebudayaan. Standar Sarana dan Prasarana Untuk Sekolah Dasar/Madrasah Ibtidaiyah (SD/MI), Sekolah Menengah Pertama/Madrasah Tsanawiyah (SMP/MTSJ), dan Sekolah Menengah Atas/Madrasah Aliyah (SMA/MA). , Pub. L. No. 24 (2007). Indonesia: Kementerian Pendidikan dan Kebudayaan RI.

Kementerian Pendidikan dan Kebudayaan. Standar Tenaga Laboratorium Sekolah/ Madrasah. , Pub. L. No. 26 (2008). Indonesia: Kementerian Pendidikan dan Kebudayaan RI.

Mardapi, D. (2008). Teknik penyusunan instrumen tes dan nontes. Yogyakarta: Mitra Cendekia.

Miles, M. B., \& Huberman, A. M. (1994). Qualitative data analysis: An expanded sourcebook. New Delhi: SAGE Publications.

Nuada, I. M., \& Harahap, F. (2015). Analisis sarana dan intensitas penggunaan laboratorium terhadap keterampilan proses sains siswa SMA Negeri Se-Kota Tanjungbalai. TABULARASA, 12(1). https://doi.org/10.24114/jt.v12i1.3234

Rahmiyati, S. (2013). Keefektifan pemanfaatan laboratorium di Madrasah Aliyah Yogyakarta. Jurnal Penelitian Dan Evaluasi Pendidikan, 11(1), 88-100. https://doi.org/10.21831/pep.v11i1.1420

Sobiroh, A. (2005). Pemanfaatan laboratorium untuk meningkatkan hasil belajar biologi siswa kelas 2 SMA Se-Kabupaten Banjarnegara semester 1 Tahun 2004/2005. Semarang: Universitas Negeri Semarang. Retrieved from http://lib.unnes.ac.id/id/eprint/3023

Sugiyono. (2016). Metode Penelitian Kuantitatif, Kualitatif, dan $R \& D$. Bandung: CV Alfabeta.

Sundari, R. (2013). Evaluasi pemanfaatan laboratorium dalam pembelajaran biologi di Madrasah Aliyah Negeri Sekabupaten Sleman. Jurnal Penelitian Dan Evaluasi Pendidikan, 12(2), 196-212. https://doi.org/10.21831/pep.v12i2.1427

Wahyunidar, W. (2017). Analisis pemanfaatan laboratorium fisika sebagai sarana kegiatan praktikum di SMA Negeri SeKabupaten Luwu Timur. Makassar: Universitas Islam Negeri Alauddin Makassar. Retrieved from http://repositori.uin-alauddin.ac.id/3123/

Yuliana, Y., Hala, Y., \& Taiyeb, A. M. (2017). Efektifitas penggunaan laboratorium terhadap motivasi dan hasil belajar IPA peserta didik SMPN 3 Palakka Kabupaten Bone. Jurnal Nalar Pendidikan, 5(1), 39$45 . \quad$ Retrieved from https://ojs.unm.ac.id/nalar/article/view/327 8 


\begin{tabular}{|c|c|c|c|c|c|}
\hline $\begin{array}{l}\mathrm{N} \\
\mathrm{o}\end{array}$ & Variabel & Aspek & Indikator & Sumber Data & $\begin{array}{c}\text { Teknik } \\
\text { Pengumpulan } \\
\text { Data } \\
\end{array}$ \\
\hline 1. & Konteks & $\begin{array}{l}\text { Daya dukung } \\
\text { kepala sekolah }\end{array}$ & $\begin{array}{l}\text { Memonitoring dan men- } \\
\text { gevaluasi pelaksanaan pro- } \\
\text { gram kegiatan sekolah }\end{array}$ & Kepala sekolah & Wawancara \\
\hline \multirow{12}{*}{2.} & \multirow{12}{*}{ Input } & \begin{tabular}{l}
\multicolumn{2}{l}{ Ketersediaan } \\
sarana dan \\
prasarana la- \\
boratorium \\
\end{tabular} & Pengadaan sarana prasarana & $\begin{array}{l}\text { Kepala labora- } \\
\text { torium }\end{array}$ & $\begin{array}{l}\text { Wawancara } \\
\text { dan observasi }\end{array}$ \\
\hline & & \multirow[t]{11}{*}{$\begin{array}{l}\text { Pengelolaan } \\
\text { laboratorium }\end{array}$} & Menyusun program kerja & $\begin{array}{l}\text { Kepala labora- } \\
\text { torium }\end{array}$ & Wawancara \\
\hline & & & Menyusun jadwal praktikum & Kepala laboran & Wawancara \\
\hline & & & $\begin{array}{l}\text { Pengaturan alat dan bahan } \\
\text { laboratorium }\end{array}$ & Laboran & Wawancara \\
\hline & & & $\begin{array}{l}\text { Pemeliharan alat dan bahan } \\
\text { laboratorium }\end{array}$ & Laboran & Wawancara \\
\hline & & & $\begin{array}{l}\text { Menjaga kedisiplinan dan } \\
\text { keselamatan laboratorium }\end{array}$ & $\begin{array}{l}\text { Laboran dan } \\
\text { guru biologi }\end{array}$ & Wawancara \\
\hline & & & $\begin{array}{l}\text { Melayani guru dan peserta } \\
\text { didik dalam pelaksanaan } \\
\text { praktikum }\end{array}$ & Laboran & Wawancara \\
\hline & & & $\begin{array}{l}\text { Pengisian format per- } \\
\text { mintaan/peminjaman } \\
\text { alat/bahan }\end{array}$ & Laboran & $\begin{array}{l}\text { Wawancara } \\
\text { dan dokumen- } \\
\text { tasi }\end{array}$ \\
\hline & & & Pengisian buku harian & Laboran & $\begin{array}{l}\text { Wawancara } \\
\text { dan dokumen- } \\
\text { tasi }\end{array}$ \\
\hline & & & $\begin{array}{l}\text { Menjaga kebersihan alat la- } \\
\text { boratorium }\end{array}$ & $\begin{array}{l}\text { Laboran dan } \\
\text { guru biologi }\end{array}$ & Wawancara \\
\hline & & & $\begin{array}{l}\text { Mengawasi pelaksanaan } \\
\text { kegiatan laboratorium }\end{array}$ & $\begin{array}{l}\text { Kepala labora- } \\
\text { torium }\end{array}$ & Wawancara \\
\hline & & & $\begin{array}{l}\text { Mengevaluasi kegiatan la- } \\
\text { boratorium }\end{array}$ & $\begin{array}{l}\text { Kepala labora- } \\
\text { torium }\end{array}$ & Wawancara \\
\hline \multirow{4}{*}{3.} & \multirow{4}{*}{ Proses } & $\begin{array}{l}\text { Pemanfaatan } \\
\text { laboratorium }\end{array}$ & $\begin{array}{l}\text { Pemanfaatan fungi laborato- } \\
\text { rium }\end{array}$ & $\begin{array}{l}\text { Guru biologi } \\
\text { dan siswa }\end{array}$ & $\begin{array}{l}\text { Wawancara } \\
\text { dan angket }\end{array}$ \\
\hline & & \multirow{3}{*}{$\begin{array}{l}\text { Kendala dalam } \\
\text { pemanfaatan } \\
\text { laboratorium }\end{array}$} & Sarana prasarana & \multirow[t]{3}{*}{ Guru biologi } & \multirow{3}{*}{$\begin{array}{l}\text { Wawancara } \\
\text { dan angket }\end{array}$} \\
\hline & & & Sumber daya manusia & & \\
\hline & & & Waktu yang tersedia & & \\
\hline 4. & Produk & Minat siswa & Perasaan senang & Siswa & Angket \\
\hline
\end{tabular}

